\title{
Domestic and Peridomestic Transmission of American Cutaneous Leishmaniasis: Changing Epidemiological Patterns Present New Control Opportunities
}

\author{
Diarmid Campbell-Lendrum/ ${ }^{+}$, Jean-Pierre Dujardin*, Eddy Martinez**, \\ M Dora Feliciangeli***, J Enrique Perez****, Laura Ney Marcelino Passerat de \\ Silans $* * * * *$, Philippe Desjeux ${ }^{* * * * * *}$
}

London School of Hygiene and Tropical Medicine, Keppel St., London WC1E 7HT, UK *UMR IRD-CNRS 9926, Montpellier, France/Instituto Nacional de Laboratorios de Salud, La Paz, Bolivia **Institut de Recherche pour le Développement, La Paz, Bolivia ***Universidad de Carabobo, Maracay, Venezuela ****Instituto de

Medicina Tropical Alexander von Humboldt, Universidad Peruana Cayetano Heredia, Lima, Peru *****FNS/SEOPE/Núcleo de Entomologia, João Pessoa, PB, Brazil *******World Health Organization, Geneva, Switzerland

Predictions that deforestation would reduce American cutaneous leishmaniasis incidence have proved incorrect. Presentations at a recent international workshop, instead, demonstrated frequent domestication of transmission throughout Latin America. While posing new threats, this process also increases the effectiveness of vector control in and around houses. New approaches for sand fly control and effective targeting of resources are reviewed.

Key words: American cutaneous leishmaniasis - deforestation - domestication - transmission - control

In undisturbed Neotropical forests, the Leishmania species which cause American cutaneous leishmaniasis (ACL) and mucocutaneous leishmaniasis (MCL), are transmitted amongst sylvatic mammals by the bite of phlebotomine sand flies. The close association between forest, wild mammal reservoirs and sand flies has previously led to predictions that deforestation would lead to local eradication of some of the most important Leishmania species, including Leishmania braziliensis in the State of São Paulo, Brazil (Sampaio 1951), and Leishmania panamensis in Panama (Herrer \& Christensen 1976).

Presentations at a recent EUROLEISH workshop (August 26, Montpellier, France) demonstrated that such optimistic predictions were far from accurate. Researchers from throughout South America described how the unprecedented deforestation of recent decades has instead been accom-

\footnotetext{
This paper is a summary of the EUROLEISH workshop on "Phlebotomine sandfly control in the New World with special reference to peridomestic transmission", $26 \mathrm{Au}-$ gust 1999, Montpellier, France, funded by the European Community.

${ }^{+}$Corresponding author. Fax: +44-20-7323.5687.

E-mail: D.Campbell-Lendrum@1shtm.ac.uk

Received 22 February 2000

Accepted 11 October 2000
}

panied by an increase in ACL and MCL cases, and documented various examples of sand fly and Leishmania species responding to human encroachment by invading the domestic environment. The increasing importance of domestic transmission is leading to reconsideration of the view that "cutaneous leishmaniasis and mucocutaneous leishmaniasis in the New World can, for the most part, be considered occupational diseases since they are directly related to professional activities in enzootic areas, especially in forests" (WHO 1990).

E Martinez (La Paz, Bolivia) described the recent definition of the role of Lutzomyia nuneztovari anglesi as a domestic vector of $L$. amazonensis in the new sub-Andean focus of Cajuta, Bolivia (Martinez et al. 1998). Lu.n. anglesi was incriminated on the basis of repeated isolation and culture of the same parasite species from sand flies as from human patients, high sand fly densities inside houses, high anthropophily, and similar geographical distributions of sand flies and human cases (Martinez et al. 1999). L. amazonensis had not previously been isolated from $L u$. $n$. anglesi, which acts as a domestic vector for $L$. braziliensis elsewhere in Bolivia (Torrez et al. 1999). This site is at a relatively high altitude (1450-2100 m a.s.l.) suggesting possible expansion of the distribution of $L$. amazonensis from previously reported foci in the lowlands of Bolivia, where it had been considered a sylvatic parasite. Infections were detected in dogs, adding to the accumulating indirect evi- 
dence that dogs act as alternative reservoirs for a range of cutaneous leishmaniasis parasites (Reithinger \& Davies 1999).

E Perez (Lima, Peru) gave an account of $L$. peruviana transmission by $L u$. verrucarum and $L u$. peruensis in the Andean highlands of Peru. In this region, transmission is overwhelmingly domestic, possibly involving domestic dogs as reservoir hosts, with indoor (rather than peridomestic) sand fly abundance providing the best predictor of transmission rate in humans. Further evidence for indoor transmission was provided by a case-control study, which identified significant house-related risk factors, and by the absence of any relationship between risk and either age or gender. However, evidence from the case-control study and from a village-based cohort study both demonstrated that risk increased with nocturnal visits to crops (e.g. for irrigation).

MD Feliciangeli (Maracay, Venezuela) described how an analysis of over 41,250 cases of cutaneous leishmaniasis reported in Venezuela reveals an increase from approximately 600 cases/ year in 1955 to $2000 / y r$ in 1998 , and a spread from sylvatic to peridomestic/domestic (Feliciangeli 1997) and even peri-urban foci (MD Feliciangeli, unpublished data). This trend has also been accompanied by a recent increase in transmission of visceral leishmaniasis [caused by $L$. infantum/ chagasi and transmitted by Lu. longipalpis (Feliciangeli et al. 1999)] and an emergence in periurban areas, associated with an increase in poverty and malnutrition (Aguilar et al. 1998). Full descriptions of reported cases are now organized in a Geographical Information System (GIS) format, allowing the rapid mapping of changes in the geographic, ecological and epidemiological pattern of transmission.

These examples constitute convincing evidence that the increasing domestication of cutaneous leishmaniasis transmission, already well characterized in deforested areas of Brazil (e.g. Tolezano 1994, Gomes 1994, Brandão-Filho et al. 1999), is widespread in Latin American.

\section{OPPORTUNITIES FOR CONTROL}

The consequent shift in the burden of disease towards children and women poses a new threat, but also presents new opportunities for control. Until recently, the interruption of ACL transmission has generally been considered unfeasible, due to its perceived sylvatic nature (Desjeux 1996). In domestic and peri-domestic transmission foci, however, interventions that decrease sand fly abundances and biting rates in and around houses may reduce disease incidence; some promising results were reported.
J-P Dujardin (La Paz, Bolivia) described early results of fieldwork in the Yungas region (Bolivia), where $L u$. $n$. anglesi is a highly endophagic vector for L. braziliensis. Pyrethroid (deltamethrin) impregnated ribbons were placed around the doors and windows of bedrooms in three villages. The intervention resulted in a marked decrease in sand fly densities inside protected houses compared to unprotected controls, and most importantly, ACL incidence was also significantly lower in protected houses (one case/400 inhabitants) during the trial compared to the same period of the previous year (10/400: Fisher's exact test, $\mathrm{P}=0.011)$, or to the control houses (5/245: Fisher's exact test, $\mathrm{P}=$ 0.032). E Martinez reported that the same intervention also greatly reduced the abundance of $L u$. $n$. anglesi inside houses in the L. amazonensis focus, from an average of 40.8 females/CDC trap/ night in unprotected control houses to 1.08 in protected houses.

E Perez described how indoor spraying of the insecticide lambdacyhalothrin (ICON) reduced transmission of L. peruviana in recent trials in Peru, consistent with results of DDT trials in the 40's. Insecticide-treated bednets have also previously been demonstrated to protect users against the bites of the ACL vector Lu. youngi in Colombia (Alexander et al. 1995), and may therefore reduce domestic ACL transmission. Taken together, these results raise hopes for insecticide-based interventions in many foci.

\section{LIMITATIONS AND FUTURE RESEARCH NEEDS}

Such interventions may not always be effective, however. MD Feliciangeli described how the use of deltamethin impregnated curtains had failed to reduce domestic abundance of $L u$. ovallesi and Lu. gomezi in Venezuela, due to the practical difficulties of blocking all entrances to irregularly constructed house. This suggests that they will consequently reduce neither human-sand fly contact nor disease transmission.

A presentation by L Passerat de Silans (João Pessoa, Brazil) further illustrated the difficulties of controlling even exclusively domestic and peridomestic transmission cycles. In Northeast Brazil, pyrethroid insecticides (deltamethrin and cypermethrin) are applied inside and outside houses to control visceral leishmaniasis. Repeated entomological surveys showed that these measures significantly reduced sand fly densities inside all houses for approximately two months, but that densities subsequently returned to pre-control levels. Bioassays suggested that this was due to gradual loss of residual insecticide activity on the adobe house walls, which are typical of the region. Outdoor densities of Lu. longipalpis remained un- 
affected throughout the trial period (Passerat de Silans et al. 1998).

These results illustrate the urgent requirement for a series of large scale intervention trials against the domestic transmission of ACL, in order to quantify the potential reduction in the burden of disease in a range of ecological settings. Even allowing for the development of appropriate control tools, the limited availability of health resources in most endemic countries will necessitate prioritization of interventions to where they will have greatest effect. For example, in São Paulo, Brazil, the current control policy for cutaneous leishmaniasis (transmitted domestically by $L u$. intermedia) is to carry out house spraying only in localities with at least two notified cases (Gomes \& Neves 1998).

Logistic constraints, however, mean that in most endemic areas case notification systems fail to achieve full geographic coverage and usually lack information on the particular parasite and vector species responsible. D Campbell-Lendrum (London, UK), described how GIS techniques may be used to extract maximum information from available data on intensity of leishmaniasis transmission and vector and parasite species. Ecological (e.g. temperature, vegetation) determinants of these distributions may be analyzed, and the observed relationships used to generate predictions for unsurveyed areas. These would improve estimates of the distribution of populations at risk, and of vector and parasite species, providing better evidence for allocation of control resources and the selection of appropriate interventions.

The final presentation and overall summary was made by P Desjeux (Geneva, Switzerland), representing the World Health Organization. Dr Desjeux thanked the workshop participants for raising awareness of the challenges posed by the changing epidemiological situation of the New World leishmaniases. He stressed that research should continue on the characterization of complex zoonotic transmission cycles (both sylvatic and domestic), which continue to make control more challenging than for anthroponotic leishmaniasis diseases in other regions. The results of the few intervention trials presented in this workshop and elsewhere, however, offer sufficient encouragement to believe that cost-effective campaigns against domestic transmission of the New World leishmaniases are an achievable goal. International co-operation will be essential to achieving this aim; vectors and parasites cross national boundaries, and this workshop confirmed that experience from one country is often of great relevance to others within the region. The sharing of research findings, the central aim of the EUROLEISH workshops, is an essential first step on this path.

\section{ACKNOWLEDGEMENTS}

To Katrin Kuhn for summarizing the workshop proceedings, and Clive Davies for comments on the manuscript.

\section{REFERENCES}

Aguilar CM, Fernandez E, Fernandez R, Cannova DC, Ferrer E, Cabrera Z, Souza WJ, Coutinho SG 1998. Urban visceral leishmaniasis in Venezuela. Mem Inst Oswaldo Cruz 93: 15-16.

Alexander B, Usma MC, Cadena H, Quesada BL, Solarte Y, Roa W, Travi BL 1995. Evaluation of deltamethrin-impregnated bednets and curtains against phlebotomine sandflies in Valle del Cauca, Colombia. Med Vet Entomol 9: 279-283.

Brandão-Filho SP, Campbell-Lendrum D, Brito MEF, Shaw JJ, Davies CR 1999. Epidemiological surveys confirm increasing burden of cutaneous leishmaniasis in north-east Brazil. Trans R Soc Trop Med Hyg 93: 488-494.

Desjeux P 1996. Leishmaniasis. Public health aspects and control. Clin Dermatol 14: 417-424.

Feliciangeli MD 1997. Hourly activity of Lutzomyia ovallesi and L. gomezi (Diptera: Psychodidae), vectors of cutaneous leishmaniasis in northcentral Venezuela. J Med Entomol 34:110-115.

Feliciangeli MD, Rodriguez N, De Guglielmo Z, Rodriguez A 1999. The re-emergence of American visceral leishmaniasis in an old focus in Venezuela. II. Vectors and parasites. Parasite 6: 113-120.

Gomes AC 1994. Sand fly vectorial ecology in the State of São Paulo. Mem Inst Oswaldo Cruz 89: 457-460.

Gomes AC, Neves VL 1998. Strategy and perspectives for the control of cutaneous leishmaniasis in the State of São Paulo. Rev Soc Bras Med Trop 31: 553-558.

Herrer A, Christenson HA 1976. Natural cutaneous leishmaniasis among dogs in Panama. Am J Trop Med Hyg 25: 59-63.

Martinez E, Le Pont F, Torrez M, Telleria J, Vargas F, Munoz M, De Doncker S, Dujardin JC, Dujardin JP 1998. A new focus of cutaneous leishmaniasis due to Leishmania amazonensis in a sub-Andean region of Bolivia. Acta Trop 15: 97-106.

Martinez E, Le Pont F, Torrez M, Telleria J, Vargas F, Dujardin JC, Dujardin JP 1999. Lutzomyia nuneztovari anglesi (Le pont \& Desjeux, 1984) as a vector of Leishmania amazonensis in a sub-Andean leishmaniasis focus of Bolivia. Am J Trop Med Hyg 61: 846-849.

Passerat de Silans LNM, Dedet JP, Arias JR 1998. Field monitoring of cypermethrin residual effect on the mortality rates of the phlebotomine sand fly Lutzomyia longipalpis in the State of Paraíba, Brazil. Mem Inst Oswaldo Cruz 93: 339-344.

Reithinger R, Davies CR 1999. Is the domestic dog $(\mathrm{Ca}$ nis familiaris) a reservoir host of American cutaneous leishmaniasis? A critical review of the current evidence. Am J Trop Med Hyg 61: 530-541.

Sampaio LF 1951. Medicina rural - o aparecimento, a 
162 Changing Patterns of ACL Transmission - Diarmid Campbell-Lendrum et al.

expansão e o fim da leishmaniose no estado de São Paulo. Rev Bras Med 8: 717-721.

Tolezano JE 1994. Ecoepidemiological aspects of American cutaneous leishmaniasis in the State of São Paulo, Brazil. Mem Inst Oswaldo Cruz 89: 427-434.

Torrez M, Lopez M, Le Pont F, Martinez E, Munoz M, Hervas D, Yaksic N, Arevalo J, Sossa D, Dedet JP,
Dujardin JPM 1999. Lutzomyia nuneztovari anglesi (Diptera: Psychodidae) as a probable vector of Leishmania braziliensis in the Yungas, Bolivia. Acta Trop 71: 311-316.

WHO 1990. Control of the leishmaniases: report of a WHO Expert Committee. Technical Report series 793. 